\title{
Dynamic PMU Compliance Test under C37.118.1aTM-2014
}

Ghiga, Radu; Wu, Qiuwei; Martin, K.; El-Khatib, Walid Ziad; Cheng, Lin; Nielsen, Arne Hejde

\section{Published in:}

Proceedings of 2015 IEEE PES General Meeting

Link to article, DOI:

10.1109/PESGM.2015.7285970

Publication date:

2015

Document Version

Peer reviewed version

Link back to DTU Orbit

Citation (APA):

Ghiga, R., Wu, Q., Martin, K., El-Khatib, W. Z., Cheng, L., \& Nielsen, A. H. (2015). Dynamic PMU Compliance Test under C37.118.1aTM-2014. In Proceedings of 2015 IEEE PES General Meeting IEEE. https://doi.org/10.1109/PESGM.2015.7285970

\section{General rights}

Copyright and moral rights for the publications made accessible in the public portal are retained by the authors and/or other copyright owners and it is a condition of accessing publications that users recognise and abide by the legal requirements associated with these rights.

- Users may download and print one copy of any publication from the public portal for the purpose of private study or research.

- You may not further distribute the material or use it for any profit-making activity or commercial gain

- You may freely distribute the URL identifying the publication in the public portal 


\title{
Dynamic PMU Compliance Test under C37.118.1 $\mathrm{a}^{\mathrm{TM}}-2014$
}

\author{
R. Ghiga, Q. Wu, K. Martin, W. Z. El-Khatib, L. Cheng and A. H. Nielsen
}

\begin{abstract}
This paper presents a flexible testing methodology and the dynamic compliance of PMUs as per the new C37.118.1a amendment published in 2014. The test platform consists of test signal generator, a Doble F6150 amplifier, PMUs under test, and a PMU test result analysis kit. The Doble amplifier is used for providing three phase voltage and current injections to the PMUs. Three PMUs from different vendors were tested simultaneously in order to provide a fair comparison of the devices. The new 2014 amendment comes with significant changes over the C37.118.1 2011 standard regarding the dynamic tests.
\end{abstract}

\section{INTRODUCTION}

PMUs are increasingly being developed in order to improve their performance. These units are considered to be among the key technologies for wide area power system protection control and monitoring [1]. The measurement data obtained from PMUs could be used to create improved control algorithms for the future power systems. Therefore, it is important to test the accuracy of the measurements in dynamic conditions since the power system itself is dynamic.

The IEEE standard for Synchrophasor Measurements for Power Systems IEEE C37.118.1-2011 [2] defines the tests that simulate different conditions of the power system such as oscillations, switching of loads and frequency ramps. The amendment to C37.118.1a [3] was published in 2014 and comes with significant changes regarding the dynamic compliance tests which consist of less strict limits for quantities like Total Vector Error (TVE), Frequency Error (FE) and Rate of Change of Frequency Error (RFE).

Dynamic compliance of PMUs is a subject that has been addressed in previous work such as [4], while [5] although published before the 2011 standard [2], provided an insight about dynamic testing.

The paper is organized as follows: Section II provides information regarding the hardware, methodology and the performed tests. Section III presents the results of dynamic compliance tests for PMUs from three different vendors, and finally Section IV concludes the paper with summarizing the contribution of the work.

R. Ghiga, Q. Wu, W. Z. El-Khatib and A. H. Nielsen are with the Center for Electric Power and Energy Engineering, Technical University of Denmark, Kgs. Lyngby 2800, Denmark; Emails: rghiga@elektro.dtu.dk, qw@elektro.dtu.dk,wzel@elektro.dtu.dk and ahn@elektro.dtu.dk

K. Martin is Senior Consultant at Electric Power Group, Los Angeles, California; Email: kenm8421@yahoo.com

L. Chen is with the Department of Electrical Engineering, Tsinghua University, Beijing 100084, China; Email: chenglin@mail.tsinghua.edu.cn

\section{PMU Testing ARChitecture And Methodology}

This section of the paper presents the laboratory hardware used for testing the PMUs and describes the methodology of the testing.

\section{A. Test Bed Description}

To generate the PMU input signals, a Doble F6150 Power System Simulator is used. Normally, this device serves as a standard stand alone test set for protection relays. This Power System Simulator is capable of delivering 3-phase AC voltages and currents with different amplitudes.

The PMUs inputs are connected directly to the test set without using additional amplifiers which reduces accuracy issues. Multiple devices can be tested simultaneously using the same input signal, providing a fair performance analysis.

As the standard [2] requires, the measurement errors of the PMUs should be calculated within $1 \%$ of the nominal signal. In order to achieve such precision, the test equipment should be able to produce signals with an accuracy around ten times higher than that as mentioned in [6]. Supposedly, the chosen simulator is capable of a precision up to $0.02 \%$ which is sufficient for this job. The Doble F6150 Power System Simulator can output signals with varying frequency, modulated amplitude and modulated phase, and it can step both phase or amplitude which covers the entire dynamic test range.

\section{B. Testing procedure}

The test process is based on the generation of waveforms required by the C37.118.1a amendment, application to the PMU and comparison of the reported PMU data with the expected result. The idea is simple and robust since a PMU estimates a synchrophasor equivalent for a given $\mathrm{AC}$ waveform. By taking a phasor equivalent model and producing the $\mathrm{AC}$ waveform that it represents with high accuracy as an electrical signal then putting it into a PMU, the resulting synchrophasor estimate should match the original phasor model.

Transient effects due to parameter change, would distort the measurements. Therefore, the tests allow enough settling time, and the sample points of transients are discarded from the analysis.

\section{Reference Phasor Definition, Measurement Evaluation and Test description}

A generalized phasor function can be obtained from a sine function with amplitude and phase modifiers as in (1):

$$
X(t)=X_{m}[g(t)] * \cos \left(\omega_{0} t+y(t)\right)
$$


Where $X_{m}$ is the nominal amplitude, $\omega_{0}$ is the nominal power system frequency, $g(t)$ is an amplitude modifying function and $y(t)$ is a phase modifying function. The corresponding phasor value is:

$$
X(n T)=\left\{X_{m} / \sqrt{2}\right\}\{g(n T)\} \angle\{y(n T)\}
$$

Where $\mathrm{nT}$ is the reporting instant. The phasor values reported by the PMU should be an estimate of this value for each given instant in time. Frequency and ROCOF are defined in (3):

$$
f(t)=\frac{1}{2 \pi} \frac{d\left(\omega_{0} t+y(t)\right)}{d t} ; \quad \operatorname{ROCOF}(t)=\frac{d f(t)}{d t}
$$

The measurement evaluation is specified in the IEEE C37.118.1 [2] and it consists of the Total Vector Error given by (4),

$$
T V E=\sqrt{\frac{\left(\hat{X}_{r}(n)-X_{r}(n)\right)^{2}+\left(\hat{X}_{i}(n)-X_{i}(n)\right)^{2}}{\left(X_{r}(n)\right)^{2}+\left(X_{i}(n)\right)^{2}}}
$$

Where $\hat{X}_{r}$ and $\hat{X}_{i}$ are the measured real and imaginary parts of the phasor and $X_{r}$ and $X_{i}$ are the real and imaginary parts of the reference phasor.

Similarly, frequency measurement error (FE) and Rate Of Change Of Frequency Error (RFE) are defined by the standard as (5) and (6),

$$
\begin{gathered}
F E=\left|f_{\text {true }}-f_{\text {measured }}\right|=\left|\Delta f_{\text {true }}-\Delta f_{\text {measured }}\right| \\
R F E=\left|(d f / d t)_{\text {true }}-(d f / d t)_{\text {measured }}\right|
\end{gathered}
$$

where $f_{\text {measure }}$ is the frequency estimated by the PMU while $f_{\text {true }}$ is the frequency of the test signal from the Doble F6150 Power System Simulator.

The dynamic compliance tests are shortly described in the following table:

TABLE I: Dynamic tests description

\begin{tabular}{|c|c|}
\hline Test Name & Varied quantity \\
\hline Amplitude modulation (Amod) & Phasor amplitude by $0.1 \mathrm{pu}$ \\
\hline Phase modulation (Pmod) & Phasor Angle by $0.1 \mathrm{rad}$ \\
\hline Frequency Ramp (Framp) & Frequency $\pm 1 \mathrm{~Hz} / \mathrm{s}$ Range $45-55 \mathrm{~Hz}$ \\
\hline Amplitude step (Astep) & $\pm 0.1 \mathrm{pu}$ \\
\hline Phase Step (Pstep) & \pm 10 degrees \\
\hline
\end{tabular}

\section{TEST RESUlts}

This section presents the results for dynamic compliance tests listed in Table for the M-performance class and $50 \mathrm{~Hz}$ reporting rate of the PMUs. The limits for TVE, FE and RFE are shown on the plots with a red line at the values defined by amendment [3] for the specific test.

1) Amplitude Modulation Test: This is one of the tests designed to determine the measurement bandwidth of the PMUs, by modulating the amplitude of the input signals (voltages and currents) with a sinusoidal waveform with a $10 \%$ modulation level. Therefore, the amplitude of the phasor should oscillate between 0.9 and 1.1 p.u. The modulation frequency range, as stated by the amendment [3] is between $0.1 \mathrm{~Hz}-5 \mathrm{~Hz}$ with increments of $0.2 \mathrm{~Hz}$. Fig 1a shows that

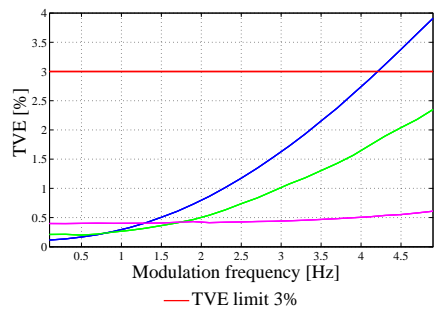

(a)

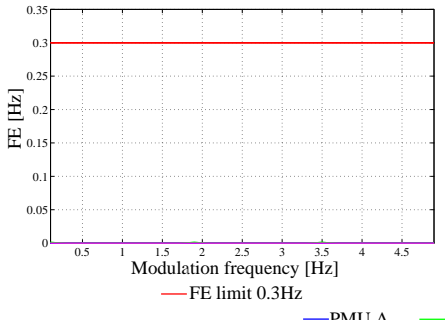

(c)



(b)

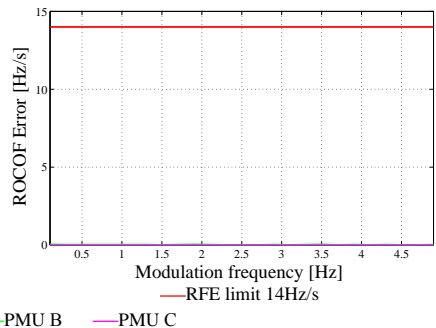

(d)
Fig. 1: Amplitude Modulation Test: a) PosSeq voltage TVE; b) PosSeq voltage amplitude at $f_{m}=5 \mathrm{~Hz}$; c) FE; d) RFE

PMU A satisfies the measurement bandwidth TVE compliance up to a modulation frequency of $4.2 \mathrm{~Hz}$, beyond which it exceeds the 3\% limit. Although the performance of PMU B decreases as the modulation frequency increases, the TVE is within the required limit. PMU $\mathrm{C}$ is measuring the inputs signals with almost constant accuracy throughout the entire modulation range. Fig $1 \mathrm{~b}$ shows the section of the test signal where the modulation frequency is $5 \mathrm{~Hz}$. It can be seen that the difference between PMU A measurement and reference amplitude is significant. This causes the TVE to exceed the $3 \%$ limit. The magenta line of PMU C is almost identical with the reference signal.

Figs 1c and 1d show that all units are measuring the frequency with high accuracy. Furthermore, only the line of PMU C is visible because it is overwriting the lines of the other two units.

2) Phase Modulation Test: This is the second test designed to verify the measurement bandwidth of the PMUs. The phase of the input signal is modulated by 0.1 radian (5.729 degrees) and the modulation frequency is the same as for the previous test. Fig 2a shows that PMU A is exceeding the 3\% limit beyond $4.5 \mathrm{~Hz}$ modulation frequency. This is due to the offset between the reference value and the measurement of PMU A visible in Fig $2 b$. The other two units satisfy the TVE compliance for phase modulation.

The frequency error is shown in Fig 2c. PMU C is the first one to exceed the threshold beyond $2.4 \mathrm{~Hz}$. PMU A satisfies the compliance up to $4.2 \mathrm{~Hz}$ modulation frequency. PMU B manages to estimate the input signal frequency with enough accuracy from start to finish. Fig $2 \mathrm{~d}$ shows the RFE. PMUs A and $\mathrm{B}$ manage to provide measurements within the required limits while unit $\mathrm{C}$ is exceeding the threshold close to $5 \mathrm{~Hz}$ modulation frequency. 


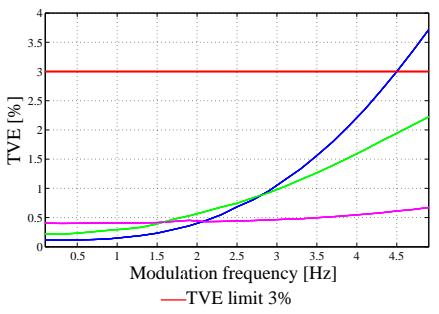

(a)



(c)

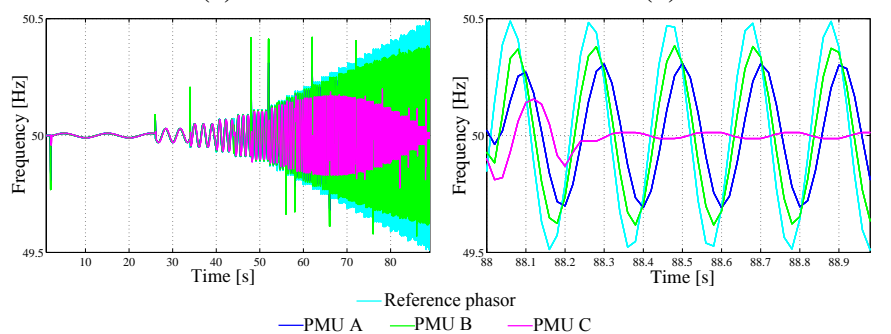

(e)

(f)
Fig. 2: Phase Modulation Test: a) PosSeq Voltage TVE; b) PosSeq Voltage amplitude at $f_{m}=5 \mathrm{~Hz}$; c) FE; d) RFE; e) Frequency; f) Frequency at $f_{m}=5 \mathrm{~Hz}$

The test modulates the phase of the input signals and the frequency $F=d($ phase $) / d t$ and it varies with the phase. Fig $2 \mathrm{e}$ shows the frequency measurement of the PMUs for the entire modulation range. PMU $\mathrm{C}$ does not manage to produce the correct measurements for the signal frequency which is why it exceeds the FE limit. Fig $2 \mathrm{f}$ shows the measurements and reference for $5 \mathrm{~Hz}$ modulation frequency. It is clear that PMU C performs poorly since it reports almost no oscillation at all. Furthermore, this figure shows that there is a delay in frequency measurement for all units.

3) Amplitude Step Test: This test in focusing on the ability of the phasor measurement unit to measure positive and negative amplitude steps that occur in dynamic power systems due to switching actions. These changes are analyzed for the available PMUs and the obtained results are presented in this section. A phasor is not expected to be accurate during highly non-linear event like a step change input. Therefore, the TVE may be high and exceed limits during the step. The test measures response time, which is the interval of time from which the TVE leaves the steady-state limit until it returns within that limit. It also checks that the response is aligned with the actual step in time (delay time) and that it does not take on extreme values during the transition (overshoot). All limits for the mentioned quantities are defined in the amendment [3].

For ease of use and understanding the time when the step occurs is chosen as $\mathrm{t}=0 \mathrm{~s}$. Therefore, the steady state prior the step is referred by negative time, while the transients and steady state after the amplitude increase are on the positive side. Moreover, the delay time can have both positive or negative values due to this reference point in time. For this test the amplitude of the signal is stepped with $0.1 \mathrm{pu}$ as shown in Fig 3a.

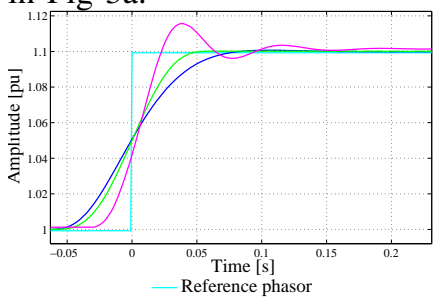

(a)

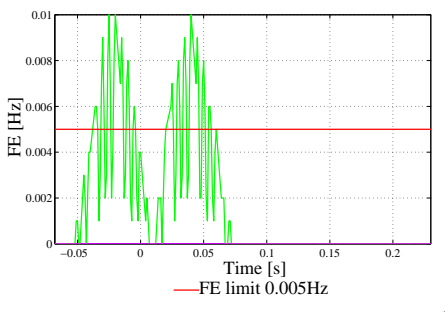

—PMU A $-\mathrm{PMU}$ B $-\mathrm{PMU} \mathrm{C}$

(c)

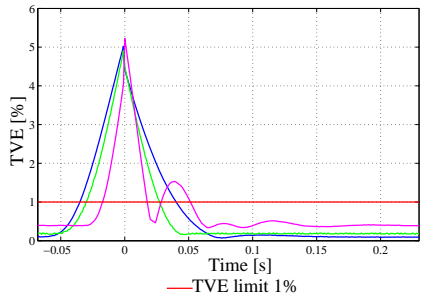

(b)

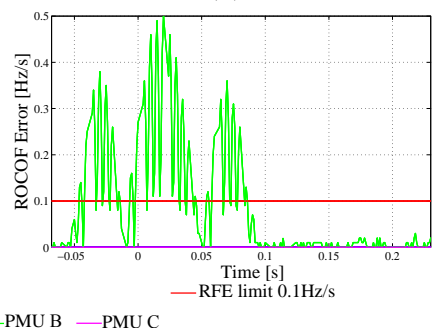

(d)
Fig. 3: Positive Amplitude Step Test: a) PosSeq Voltage amplitude; b) PosSeq Voltage TVE; c) FE; d) RFE

It can be seen that each device reacts differently to a step change. The following table presents the calculated response time, delay time, over and undershoot as well as the limits specified in C37.118.1a.

TABLE II: Positive Amplitude Step, Overshoot and Undershoot compliance under C37.118.1a for M-class performance

\begin{tabular}{|c|c|c|c|c|}
\hline Fs & \multicolumn{3}{|c|}{$50 \mathrm{~Hz}$} \\
\hline & \multicolumn{2}{|c|}{ Overshoot } & \multicolumn{2}{|c|}{ Undershoot } \\
\hline & $\begin{array}{c}\text { Calculated } \\
{[\%]}\end{array}$ & $\begin{array}{c}\text { Limit } \\
{[\%]}\end{array}$ & $\begin{array}{c}\text { Calculated } \\
{[\%]}\end{array}$ & $\begin{array}{c}\text { Limit } \\
{[\%]}\end{array}$ \\
\hline PMU A & 1.4 & \multirow{2}{*}{10} & 0 & \multirow{2}{*}{10} \\
\cline { 1 - 1 } & & 0 & \\
\hline PMU B & 1.04 & & 3.19 & \\
\hline
\end{tabular}

TABLE III: Positive Amplitude Step Response and Delay Times compliance under C37.118.1a for M-class performance

\begin{tabular}{|c|c|c|c|c|c|c|c|c|}
\hline \multirow[t]{3}{*}{ Fs } & \multicolumn{8}{|c|}{$50 \mathrm{~Hz}$} \\
\hline & \multicolumn{6}{|c|}{$\begin{array}{l}\text { Response Time } \\
{[\mathrm{ms}]}\end{array}$} & \multicolumn{2}{|c|}{$\begin{array}{l}\text { Delay Time } \\
{[\mathrm{ms}]}\end{array}$} \\
\hline & \multicolumn{2}{|c|}{ TVE } & \multicolumn{2}{|c|}{$\mathrm{FE}$} & \multicolumn{2}{|c|}{ RFE } & & \\
\hline PMU A & 75 & \multirow{3}{*}{140} & 0 & \multirow{3}{*}{280} & 0 & \multirow{3}{*}{280} & -1.14 & \\
\hline PMU B & 57 & & 98 & & 132 & & -0.4 & 5 \\
\hline PMU C & 68 & & 0 & & 0 & & 2.83 & \\
\hline
\end{tabular}

Table III shows the response and delay times for each PMU. The limits specified in the amendment [3] are colored in red, and are valid for the $50 \mathrm{~Hz}$ reporting rate which was used in these tests. Results in Table III show that all units are within 
the required response and delay times, which is consistent with Figs 3b, 3c, and 3d. The negative amplitude step has similar results and is not presented in this paper.

4) Phase Step Test: Line switching operations can cause step changes in the phase of the power system. Similar to the amplitude step, the phase step test focuses on the ability of the PMUs to follow these changes.

Fig 4a shows that the PMU A is quite different from the other two. Its performance is worse both in overshoot and delay time and the reason is not clear. PMUs B and C perform similar as in the Amplitude Step test. The FE and RFE are significantly different for this test as shown in Fig $4 \mathrm{c}$ and Fig $4 \mathrm{~d}$, respectively. This is due to the relation between phase, frequency and ROCOF which are defined in (3).

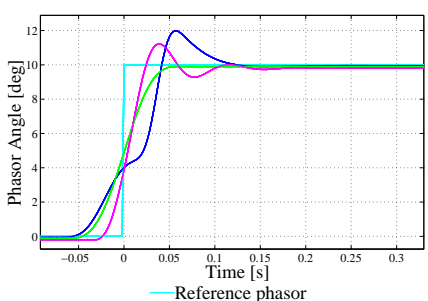

(a)

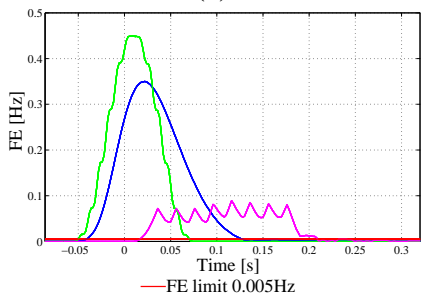

(c)

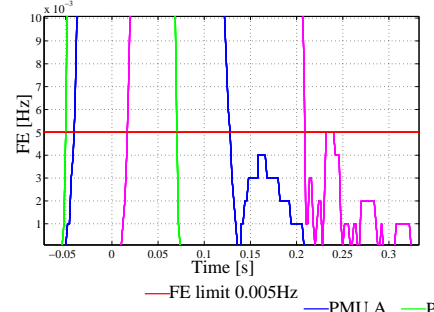

(e)

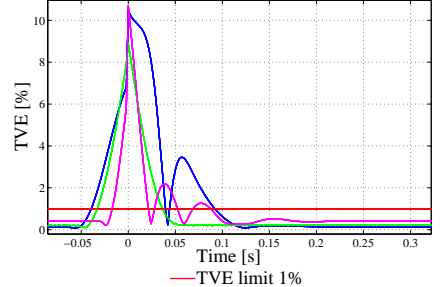

(b)

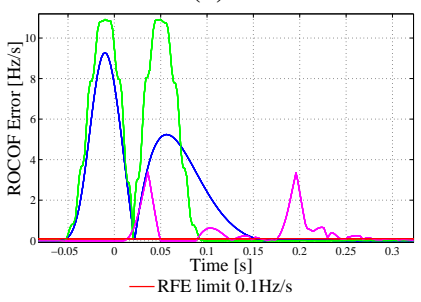

(d)

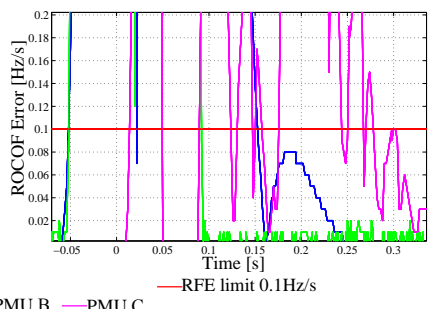

(f)
Fig. 4: Phase Step Test: a) PosSeq Voltage amplitude; b) PosSeq Voltage TVE; c) FE; d) RFE; e) FE (zoomed in) f) RFE (zoomed in)

Figs $4 \mathrm{e}$ and $4 \mathrm{f}$ are zoomed image of the Fe and RFE plots in order to clearly show where the limit line is. These plots can be used to verify the results in Table V. Overshoot and undershoot values are shown in Table IV.

5) Frequency ramp Test: The frequency ramp test was introduced by the 2011 standard [2]. It emulates a system separation scenario when the generation and load are imbalanced and the system frequency might increase or decrease depending on case. In order to cover both scenarios, for this test the injected signal has constant amplitude and phase while the frequency is changing linearly with a slope of $\pm 1 \mathrm{~Hz} / \mathrm{s}$.
TABLE IV: Positive Phase Step, Overshoot and Undershoot compliance under C37.118.1a for M-class performance

\begin{tabular}{|c|c|c|c|c|}
\hline Fs & \multicolumn{4}{|c|}{$50 \mathrm{~Hz}$} \\
\hline & \multicolumn{2}{|c|}{ Overshoot } & \multicolumn{2}{|c|}{ Undershoot } \\
\hline & $\begin{array}{c}\text { Calculated } \\
{[\%]}\end{array}$ & $\begin{array}{c}\text { Limit } \\
{[\%]}\end{array}$ & $\begin{array}{c}\text { Calculated } \\
{[\%]}\end{array}$ & $\begin{array}{c}\text { Limit } \\
{[\%]}\end{array}$ \\
\hline PMU A & 19.8 & \multirow{3}{*}{10} & 0.9 & \multirow{3}{*}{10} \\
\hline PMU B & 0 & & 1.18 & \\
\hline PMU C & 12.2 & & 7.17 & \\
\hline
\end{tabular}

TABLE V: Positive Phase Step Response and Delay Times compliance under C37.118.1a for M-class performance

\begin{tabular}{|c|c|c|c|c|c|c|c|c|}
\hline \multirow[t]{3}{*}{ Fs } & \multicolumn{8}{|c|}{$50 \mathrm{~Hz}$} \\
\hline & \multicolumn{6}{|c|}{$\begin{array}{l}\text { Response Time } \\
{[\mathrm{ms}]}\end{array}$} & \multicolumn{2}{|c|}{$\begin{array}{c}\text { Delay Time } \\
{[\mathrm{ms}]}\end{array}$} \\
\hline & \multicolumn{2}{|c|}{ TVE } & \multicolumn{2}{|c|}{ FE } & \multicolumn{2}{|c|}{ RFE } & & \\
\hline PMU A & 131 & \multirow{3}{*}{140} & 169 & \multirow{3}{*}{280} & 205 & \multirow{3}{*}{280} & 21.41 & \\
\hline PMU B & 69 & & 120 & & 144 & & 0.63 & 5 \\
\hline PMU C & 104 & & 223 & & 264 & & 4.35 & \\
\hline
\end{tabular}

The range of the frequency used for this test is from 45 $\mathrm{Hz}$ up to $55 \mathrm{~Hz}$. Fig 5a shows the reference and measured frequencies along the mentioned range. A detailed view is shown in Fig 5b where it is visible that all PMUs have a delay in the measurement. It could be the effect of the filtering of these devices. However, the reported frequency increases and decreases linearly which reveals no issues with the frequency estimation algorithms.

Fig 6a and Fig 6b show that PMU B does not measure correctly the amplitude of the phasor. It is probably caused by the frequency tracking algorithm. It manages to adjust the measurement window at the points where the amplitude is reported with accuracy. However, as the frequency ramps up, the tracking method of the PMU does not keep up and the amplitude of the phasor is measured incorrectly. PMU C shows a different behavior. As the frequency is linearly increasing, the unit measures amplitude with higher accuracy. On the other hand the TVE exceeds the $1 \%$ limit at $55 \mathrm{~Hz}$ which means that the angle is responsible. This is also what is happening with PMU A.

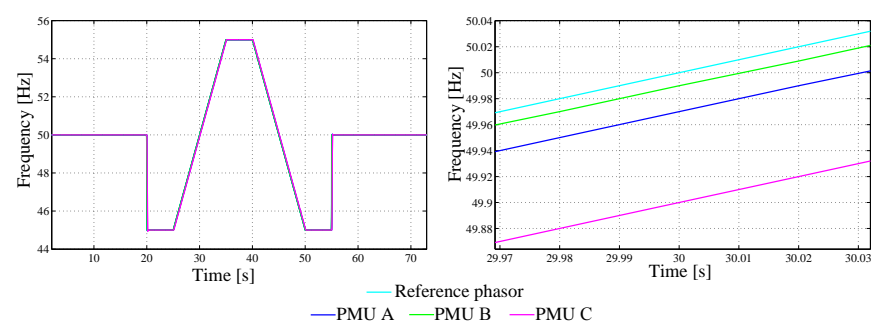

(a)

(b)

Fig. 5: Frequency Ramp Test: a) Signal frequency; b) Zoomed view at $50 \mathrm{~Hz}$

Fig 6c shows that all PMUs are exceeding the FE limit, and this is due to the delay in the frequency measurement. Furthermore, the errors show that the PMUs performance is constant for entire ramp which supports the idea that the delay is due to slow filtering. All units report an accurate ROCOF 


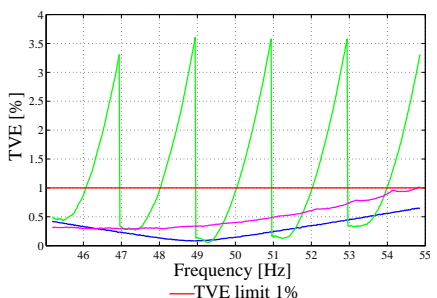

(a)

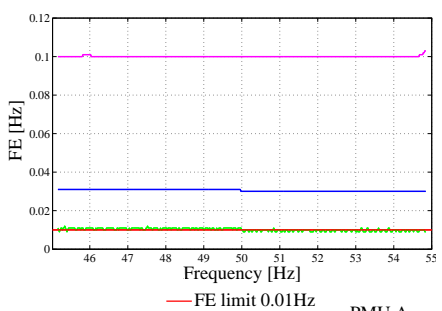

(c)

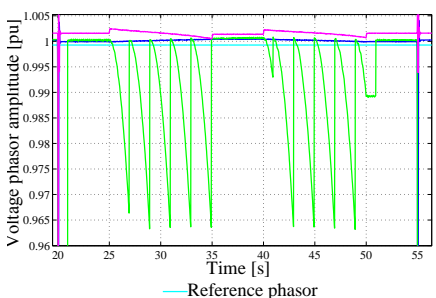

(b)

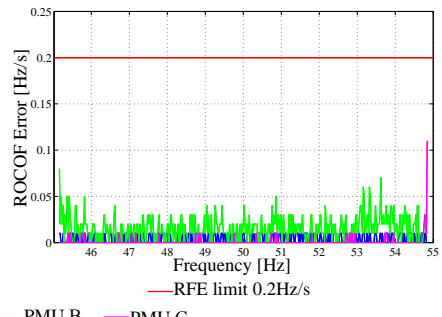

(d)
Fig. 6: Frequency Ramp: a) PosSeq Voltage TVE; b) PosSeq Voltage Amplitude; c) FE; d) RFE

as shown in Fig 6d.

The overall performance of the dynamic compliance tests under the M-class requirements of the 2014 amendment [3] are shown in the following tables:

TABLE VI: Pass/Fail for Amplitude Modulation, Phase Modulation, and Frequency Ramp Tests under C37.118.1a

\begin{tabular}{|c|c|c|c|c|c|c|c|c|c|}
\hline $\begin{array}{c}\text { Test } \\
\text { M-class }\end{array}$ & \multicolumn{3}{|c|}{ Amod } & \multicolumn{3}{|c|}{ Pmod } & \multicolumn{3}{|c|}{ Framp } \\
\hline Fs & \multicolumn{3}{|c|}{$50 \mathrm{~Hz}$} & \multicolumn{3}{|c|}{$50 \mathrm{~Hz}$} & \multicolumn{3}{|c|}{$50 \mathrm{~Hz}$} \\
\hline Error & TVE & $\mathrm{FE}$ & RFE & TVE & $\mathrm{FE}$ & RFE & TVE & $\mathrm{FE}$ & RFE \\
\hline PMU A & $\mathrm{F}$ & $\mathrm{P}$ & $\mathrm{P}$ & $\mathrm{F}$ & $\mathrm{F}$ & $\mathrm{P}$ & $\mathrm{P}$ & $\mathrm{F}$ & $\mathrm{P}$ \\
\hline PMU B & $\mathrm{P}$ & $\mathrm{P}$ & $\mathrm{P}$ & $\mathrm{P}$ & $\mathrm{P}$ & $\mathrm{P}$ & $\mathrm{F}$ & $\mathrm{F}$ & $\mathrm{P}$ \\
\hline PMU C & $\mathrm{P}$ & $\mathrm{P}$ & $\mathrm{P}$ & $\mathrm{P}$ & $\mathrm{F}$ & $\mathrm{F}$ & F & $\mathrm{F}$ & $\mathrm{P}$ \\
\hline
\end{tabular}

TABLE VII: Pass/Fail for Positive Amplitude/Phase Step Tests under C37.118.1a

\begin{tabular}{|c|c|c|c|c|c|c|}
\hline Test & \multicolumn{6}{|c|}{ Astep / Pstep } \\
\hline Fs & \multicolumn{6}{|c|}{$50 \mathrm{~Hz}$} \\
\hline & \multicolumn{3}{|c|}{$\begin{array}{c}\text { Response } \\
\text { Time }\end{array}$} & \multirow{2}{*}{$\begin{array}{l}\text { Delay } \\
\text { Time }\end{array}$} & \multirow{2}{*}{ Overshoot } & \multirow{2}{*}{ Undershoot } \\
\hline Error & TVE & $\mathrm{FE}$ & RFE & & & \\
\hline PMU A & $\mathrm{P} / \mathrm{P}$ & $\mathrm{P} / \mathrm{P}$ & $\mathrm{P} / \mathrm{P}$ & $\mathrm{P} / \mathrm{F}$ & $\mathrm{P} / \mathrm{F}$ & $\mathrm{P} / \mathrm{P}$ \\
\hline PMU B & $\mathrm{P} / \mathrm{P}$ & $\mathrm{P} / \mathrm{P}$ & $\mathrm{P} / \mathrm{P}$ & $\mathrm{P} / \mathrm{P}$ & $\mathrm{P} / \mathrm{P}$ & $\mathrm{P} / \mathrm{P}$ \\
\hline PMU C & $\mathrm{P} / \mathrm{P}$ & $\mathrm{P} / \mathrm{P}$ & $\mathrm{P} / \mathrm{P}$ & $\mathrm{P} / \mathrm{P}$ & $\mathrm{F} / \mathrm{F}$ & $\mathrm{P} / \mathrm{P}$ \\
\hline
\end{tabular}

\section{CONCLUSION}

This paper presents a method that can be used to test any kind of PMU using any test defined by the C37.118.1 standard. The dynamic compliance of PMUs from three different vendors was verified under the 2014 amendment [3] requirements.

The devices under test were built to satisfy the 2005 standard which did not define the dynamic compliance tests. Furthermore, the frequency ramp test was introduced in 2011 therefore these PMUs might lack the necessary algorithms to pass this test.

The analysis software is developed "in-house" entirely in Matlab and it can be easily adapted to future changes of the performance requirements. Therefore, the tools presented in this paper make a good option when considering building a test setup for instrument validation, regarding portability, availability, and flexibility.

\section{ACKNOWLEDGMENT}

The authors would like to thank the Nordic Energy Research (Norden) which supports the Smart transmission grid operation and control (StronGrid) project and made this research possible.

\section{REFERENCES}

[1] A. Bose, "Smart transmission grid applications and their supporting infrastructure", IEEE Trans on Smart Grid, vol. 1, pp. 1119, 2010.

[2] IEEE Standard for Synchrophasor Measurements for Power Systems IEEE Std C37.118.1 TM $_{-2011 .}$

[3] Amendment 1: Modification of Selected Performance Requirements IEEE Std C37.118.1 $\mathrm{a}^{\mathrm{TM}}-2014$ (Amendment to IEEE Std C37.118.1 ${ }^{\mathrm{TM}}$ 2011).

[4] Narendra, K., Gurusinghe, D. R., \& Rajapakse, A. D. Dynamic Performance Evaluation and Testing of Phasor Measurement Unit (PMU) as per IEEE C37. 118.1 Standard.

[5] K. Martin, T. Faris, J. Hauer, "Standardized Testing of Phasor Measurement Units", Fault and Disturbance Analysis Conference 2006, Georgia Tech, Atlanta, GA.

[6] IEEE Guide for Synchronization, Calibration, Testing, and System Protection and Control - IEEE C37.242

[7] D. E. Bakken, A. Bose, C. H. Hauser, D. E. Whitehead, and G. C. Zweigle, "Smart generation and transmission with coherent, real-time data", Proceedings of the IEEE, vol. 99, no. 6, pp. 928951, 2011.

[8] IEEE C37.118-2005, IEEE Standard for Synchrophasors in Power Systems.

[9] IEEE Standard for Synchrophasor Data Transfer for Power Systems IEEE Srd C37.118.2 $2^{\mathrm{TM}}-2011$.

[10] Garcia-Valle, R., Yang, G. Y., Martin, K. E., Nielsen, A. H., \& Ostergaard, J. (2010, October). DTU PMU laboratory developmentTesting and validation. In Innovative Smart Grid Technologies Conference Europe (ISGT Europe), 2010 IEEE PES (pp. 1-6). IEEE.

[11] Almas, Muhammad Shoaib, Jako Kilter, and Luigi Vanfretti. "Experiences with steady-state PMU compliance testing using standard relay testing equipment." Electric Power Quality and Supply Reliability Conference (PQ), 2014. IEEE, 2014.

[12] Martin, Kenneth E., John F. Hauer, and Tony J. Faris. "PMU testing and installation considerations at the Bonneville power administration." Power Engineering Society General Meeting, 2007. IEEE. IEEE, 2007.

[13] Doble, "F6150 Power System Simulator" - https://www.doble.com/parts/ files/File/F6150 \_Brochure $\backslash$ _04-08.pdf

[14] StreamReader software developped by Bonneville Power Administration. 